\title{
Os três pilares da democracia
}

\section{A. Almeida Júnior}

Pela mão amiga de ex-alunos meus, da Faculdade de Direito, sou trazido hoje perante êste auditório, para que diga algumas palavras a propósito do problema que na atualidade empolga a opinião pública brasileira. E' óbvio que me refiro ao problema político da redemocratização das nossas instituições.

Os jovens advogados que me convidaram estavam, creio eu, bem informados sôbre a minha formação cultural. Sabiam que, apesar de professor numa escola jurídica, não sou jurista, e que, portanto, na melhor das hipóteses, só poderei encarar o meu tema através de dois prismas: o da educação e o da medicina social. Conheciam também êsses amáveis ex-alunos, por experiência pessoal, o exato alcance dos recursos dialéticos do conferencista, os quais, como acentuou com precisão um deles, apresentam a nola característica (e, digamos entre nós, a nota um pouco enfadonha...) do didatismo. Vale dizer, pelo avêsso, que, quando o orador assoma à tribuna, a musa da eloquência discretamente se afasta. Deviam estar informados, enfim (e se não estavam cometeram gravíssima imprudência!), de que, embora simples soldado raso, tenho posição definida numa das agremiações políticas que aguardam, ansiosas, o dia 2 de dezembro, para levarem às urnas o voto que elegerá o presidente legal dêste País e que restabelecerá, entre nós, o regime democrático.

(1) Conferência por ocasião da instalação do Comité Democrático dos Advogados de São Paulo, a 1.0 de setembro de 1945. 
Agradeço, desvanecido, a distinção do convite, e assinalo, ao mesmo tempo, o alto espírito de tolerância que o orientou, o qual mostra desde logo que êste cenáculo, agora inaugurado, será de fato uma tribuna para a livre exposição e debate das doutrinas políticas que se apresentem como sucetíveis de conduzirem o nosso povo à felicidade que êle merece, e que reclama.

\section{Limitação do tema}

O título desta conferência é propositadamente restritivo. Não me proponho discorrer sôbre o conteudo ideológico do regime democrático, e sim, únicamente, a respeito das bases em que êle assenta: os três pilares da democracia. E, visto que me saiu, logo de início, êsse rótulo cabalístico, eu poderia, no tocante à definição de atitudes, conservar-me no domínio da mística e do impressionismo. Como há os "queremistas," que "querem porque querem", sem maiores explicações, eu apenas diria que gosto da democracia... porque gosto!

Com efeito, não é só em matéria de filosofia que a orientação do indivíduo depende (segundo afirma William James) do seu temperamento. Este fator irracional tam. bém pesa nas predileções políticas. Há reis que por natureza são democráticos, como há presidentes, eleitos ou não, cujas íntimas tendências se volvem para a tirania. Não cheguemos ao exagêro de falar, como falariam Lombroso ou Ferri, em ditador-nato, em democrata-nato; mas o que se pode dizer é que autocracia ou democracia resultam muito das inclinações pre-lógicas do coração. Existem homens (e o Brasil infelizmente os conhece!) que, digam êles o que disserem, jamais deixarão de pender para as formas autocráticas de govêrno. O rei Lear, mesmo louco, era rei até à raís dos cabelos: êstes, a que me refiro, são anti-democráticos até à medula dos ossos. 


\section{Definição e evolução da democracia}

Evitemos o terreno movediço das definições. Se Lincoln costumava repetir que a democracia é o govêrno do povo, pelo povo e para o povo, aqui no hemisfério sul se insinuou, não faz muito tempo, que govêrno democrático é aquele que satisfaz os interêsses do povo. Neste derradeiro sentido, que mostra como até os dicionários estão sob o perigo dos golpes de Estado, Hitler e Mussolini reclamariam para si o privilégio da adoção de novas técnicas rigorosamente democráticas, pois os massacres de judeus, a noite dos longos punhais, o assassínio de Matteoti, o manganelo e os campos de concentração foram levados a efeito, segundo êles, para satisfazer os interêsses do povo.

"A fórmula que compreenda todos os tipos de democracia (opina LoRd Bryce) ainda está por ser encontrada." De um lado, os teoristas da Política não falam numa democracia, mas em muitas. De outro, a prática do regime através das épocas e dos lugares, tem sido igualmente flexível. A democracia romana diferio, outrora, da democracia ateniense, assim como hoje as instituições democráticas norte-americanas se distanciam das que imperam na Inglaterra. Expressando-me como estudante de Biologia, sinto-me tentado a dizer que a democracia, o mais alto produto da evolução política, tem seiva como os vegetais, tem sańgue como os animais, e, à maneira dos seres vivos, constantemente se modifica para melhor se adaptar ao seu tempo e ao seu meio. "A democracia é evolucionista", escreveu o Presidente Benes. "Sabe que nenhuma ordem social é ou pode ser perfeita, e que uma sociedade ideal e perfeita não existe, pois é inatingivel em virtude das próprias fraquezas humanas. Mas crê na possibilidade do aperfeiçoamento e do progresso da humanidade." 


\section{O drama da ev|olução democrática}

O drama característico da evolução da democracia vem sendo a luta entre a sua própria fôrça interior, como ideal que procura afirmar-se, e a fraqueza do seu sustentáculo material. $O$ infante cresceu súbitamente em estatura e pêso, sem que o tivesse acompanhado no ritmo evolutivo a capacidade coordenadora dos membros e do equilíbrio. Com efeito, da república ateniense à república norte-americana, tem visto a democracia rápidamente expandir-se a respectiva base demográfica, em busca de justificação cada vez mais objetiva da sua natureza. Mas êsse mesmo alargamento, que lhe é inerente e imprescindivel, êsse crescente apêlo a novas classes sociais para comparticiparem da atuação política, se lhe aumenta progressivamente a vitalidade, também dia a dia lhe agrava o perigo da desorienta. ção. Em suma, a mesma causa produz consequências di-. vergentes: revigora os músculos e desnorteia o cérebro; é fôrça física e é fraqueza espiritual.

Já quatro séculos antes de Cristo, Platão, apreciando o regime democrático, declarava, com filosófica ironia: " $\mathrm{E}$ ' uma encantadora forma de govêrno, cheia de variedade $e$ de desordem, e que atribúi uma espécie de igualdade não só aos iguais, mas também aos desiguais." Aristóteles, pouco depois, testemunhando, talvez, a desintegração política da Grécia, sentia análogas apreensões. A democracia, no seu entender, simples perversão do regime constitucional, levaria à desordem, pois nela a responsabilidade do govêrno cabe, não aos que possuem, mas aos necessitados, aos indigentes, isto é, aos que não pensam senão em atender à grosseria dos instintos. Passam-se os séculos; sucedem-se as revoluções de caráter democrático; mas o temor persiste. $\mathrm{H}_{\mathrm{A}}=$ MILToN, na jovem república norte-americana, repetindo a seu modo a critica dos gregos, afirma: "o povo é turbulento e inconstante, raramente julga com exatidão". Subentende-se que êsse povo - turbulento e inconstante - não julga com 
exatidão porque, em lugar de examinar os fatos diretamente, coloca entre êstes e o seu aparelho investigador o prisma dos apetites. "A essência do govêrno democrático (dizia VERGENNE) é sempre a inveja". Ainda hoje, estudando o problema psicodinâmico da democracia, Thomaz French encontra a inveja entre os seus motivos ocultos: cada cidadão renuncia aos respectivos impulsos de ascendência, contanto que os outros façam o mesmo...

Ora, havemos de convir em que será dificil governar os povos com sabedoria, tendo-se por apoio a ignorância e a miséria; ouvindo-se, de um lado, o clamor da turbulência, e, de outro, os cochichos da inveja. Como chegar, através dêsses feios caminhos, à realização da felicidade humana? Como viver em democracia?

\section{Democracia e demagogia}

Os receios de Aristóteles ainda uma vez previram as consequências: entregar ao povo o govêrno da república, não é instalar a democracia, e sim abrir as portas à demagogia. "Onde o povo manda", disse êle, "onde o povo manda e as leis não o contêm, pululam os demagogos." Isto, sim, é que é uma verdade. O regime dos demagogos, e não a democracia, é que Aristóteles deveria desde logo ter chamado de perversão. Em rasgo genial de intuição psicológica, pinta Shakespeare, através de quadros de uma de suas tragédias, o demagogo em ação, a explorar a ignorância, a miséria, os apetites da multidão, para o fim de cavalgá-la. 0 revolucionário JACK CADE propõe o seu programa de reformas: "todos comerão e beberão à minha custa" (exclama aos seus adeptos); "todos os bens serão comuns"; "todos andarão vestidos do mesmo modo, para que pareçam irmãos." E pressentindo que o império da lei e do direito é o principal adversário da demagogia, conclúi: "mataremos todos os juristas!" 
As duas condições antagônicas - de um lado, o anșeio pela democracia, a reclamar a plena participação do povo no govêrno; de outro, a incapacidade política dêsse mesmo povo, a contra-indicar essa participação - colocam a sociedade humana em face de angustioso dilema. Ou contentar aquele anseio, e então cair na demagogia; ou atender a esta restrição, e nesse caso deixar que prevaleçam oligarcas e tiranos.

A Itália de 1922 (para só falarmos dos casos recentes), a Alemanha de 1933, o Brasil de 1937, enveredaram por êste último caminho. Expresso ou implícito, o argumento era idêntico ao contido nas críticas dos gregos: a incapacidade do povo para orientar-se; a sabedoria política como privilégio de uns poucos, representados êsses poucos, nos casos citados, por ditadores infalíveis e pelos áulicos que os ditadores escolhessem. De acôrdo com a sintese de Bertrand Russel a respeito da eclosão dos regimes fascistas (fenômeno a que todos nós tivemos a desventura de assistir), a coisa se efetiva em duas etapas. A primeira é a reunião, sob um lider mais ou menos enérgico e astucioso, de certo número de homens que possuam, em proporção maior do que a usual, condições de ociosidade, de brutalidade e de estupidez. A segunda etapa consiste em enfeitiçar os imbecís e em amordaçar os que enxergam; àqueles, mediante a excitação emocional; a êstes, pelo terror. Essa técnica, diz Bertrand RusSELL, é velha como as montanhas; foi posta em prática em tôdas as cidades gregas, e os modernos não fizeram mais do que aumentar-lhe as proporções.

Em outras palavras, são os regimes nazi-fascistas, e não os democráticos, os que mais se servem da muleta da demagogia. "Pode-se dizer, e é verdade — assevera Mannheim - que certos govêrnos (o fascismo, o nazismo) apelam frequentemente para as reservas irracionais, e, procurando uniformizar as tendências sociais e politicas e eliminar os atritos decorrentes do espírito crítico, da diversidade de grupos e das diferenças individuais, tendem, em última análise, a instalar a unanimidade massiça, a estabelecer um nivela- 
mento pelo inferior e a abaixar, em consequência, o nível espiritual." Comentando tal observação, escreve o prof. Fernando Azevedo: "Esse apêlo das ditaduras às reservas irracionais, emotivas, das massas, com o propósito de agir sôbre os instintos e paixões e provocar-lhes reações periódicas, - uma das manifestações mais inquietantes da "desracionalização" do pensamento, ou da regressão geral e conciente do pensamento racional, é que constitúi a grande crise do mundo moderno. E' a guerra de morte do "sum" (filosofia existencial) contra o "cogito" (filosofia racionalista.)"

\section{O povo "quer jå"}

Sejamos justos, e não queiramos ver nas democracias de antes da última guerra, o paraiso que elas não eram. Muitos dos seus líderes, imitando a conduta de Cesar e de Pompeu, diziam ao povo mais ou menos isto: damos-te inteira liberdade política; vota em quem quizeres; todavia, só terás direito à ração oficial de pão, se votares conosco. Mas o ditador da nova escola vai além, pois parodia e completa o demagogo de Shakspeare: "Asseguro-te a ração de pão (diz êle), contanto que me deixes governar-te à minha moda. Come e cala-te!" Para aqueles, o homem do povo, quase todo espírito e quase nada substância, será capaz de crescer e engordar alimentado apenas com os eflúvios da liberdade. Para êstes, o povo se resume num estômago. Tivéssemos entretanto de escolher entre os velhos regimes democráticos e as ditaduras que os sucederam, creio que os mais avisados não trepidariam: antes as formas de govêrno que, embora imperfeitas, caminham para a frente, do que as que em si mesmas são um retrocesso.

Todavia, o dilema que a situação nos apresenta não é bem êsse. Pode-se até dizer que nem sequer existe diante de nós qualquer dilema. O povo de agora, o do Brasil, o da América, o do mundo inteiro; o povo que venceu com o seu 
sangue o monstro da tirania e que decidio, com a sua vitória, o rumo definitivo da civilisação, quer ser, de hoje em diante, corpo, e também espírito. Reclama um lugar à mesa onde mate a fome, e outro, nas assembléias legislativas e nos postos de govêrnos, de onde possa compartilhar da direção da comunidade.

$\mathrm{E}$ inegável ainda hoje a procedência dos receios de PlaTÃo e de Aristóteles; o povo não está maduro para governar-se; é alto o seu indice de ignorância, reduzida a sua capacidade de escolha, violentas e contraditórias as suas paixões. Mas demonstraram porventura excepcional superioridade, em relação a êsse mesmo povo, os homens que, pelo Brasil em fora, estiveram, durante quarenta anos, à frente das oligarquias? Administraram a contento e sem apetites os negócios da república os que últimamente, pela astúcia e pela fôrça, empolgaram o poder? Conseguiram aqueles assegurar ao menos a liberdade política? Cumpriram êstes a promessa mínima de matar a fome aos que não nasceram ricos? Evidentemente, não.

Desde, pois, que uns e outros falharam até mesmo ao compromisso que assumiram, que o povo, enfim, o povo soberano e legitimamente organizado em partidos, reivindique as suas prerrogativas e escolha, pelo voto livre, o seu govêrno. Êle não está preparado, é certo, como também não o estavam os ingleses e os americanos, quando principiaram a votar. Pois que se prepare no próprio atrito da experiência. "Learning by doing". Os ditadores, visto que são infaliveis e inspirados por Deus, não têm o direito de errar: o povo tem êsse direito. Os candidatos propostos por um partido podem não dar certo: o povo, na eleição seguinte, preferirá os candida* tos do partido oposto. "A periodicidade das eleições (sublinha Salvemini) decorre exatamente da falibilidade do povo."

Por isso, aos que porventura perguntarem ao povo brasileiro quando quer êle tomar conta da máquina do Estado, que a resposta seja idêntica á do nosso jovem imperador: "Quero já!" 


\section{Os dois primeiros pilares}

Nada disto, entretanto, nos fará perder de vista o fato fundamental de que cada democracia vale o que valem os seus cidadãos. Se os govêrnos oligárquicos podem contentar-se com valorizar apenas a sua meia dúzia de líderes, é da essência mesma do regime democrático (e nisto está em grande parte o seu mérito) que o povo se esforce por seu próprio desenvolvimento.

O primeiro e o segundo pilares, que havemos de ir assentando afim de que o Brasil se conduza airosamente na tarefa de governar-se, estão de tal forma prêsos um ao outro, que não é conveniente isolá-los, nem estudá-los separadamen te. A saude depende da educação, tanto quanto a educação depende da saude; e a insuficiência de ambas se responsabiliza, em parcelas dificeis de precisar, pelas diferenças físicas e mentais que hierarquizam os homens, colocando a uns sob o domínio dos outros.

\section{Hereditariedade e democracia}

Os adversários da democrácia apontam, escandalizados, para o fato de serem os homens profundamente desiguais em suas capacidades. Recorde-se o comentário irônico de Platão: “encantadora forma de govêrno, que iguala até os desiguais..."

"Alguns me perguntam (diz ConkLin, biologista contemporâneo): se acreditais na hereditariedade, como admitís a democracia? Outros indagam: se acreditais na democracia, como admitís a hereditariedade?"

Ignoram, ou esquecem, êsses adversários, um fato fundamental. E é que a maior proporção das desigualdades físicas, e principalmente das desigualdades mentais, que inferiorizam os homens, provêem, não da hereditariedade (como parecem supôr), mas das fồrças ambientais. Venho, 
a êsse propósito, coligindo há vários anos, e muito de caso pensado divulgando, quer em conferências, quer em aulas ou publicações, o que a investigação científica tem apurado, no que concerne à ação das doenças, das deficiências alimentares e dos defeitos de educação, sôbre o desenvolvimento ida criatura humana.

"Vi uma vez (escreve Gilberto Freyre), depois de mais de três anos massiços de ausência do Brasil, um bando de marinheiros nacionais - mulatos e cafusos - descendo não me lembro se do "São Paulo" ou do "Minas", pela neve mole do Brooklin. Deram-me a impressão de caricaturas de homens." E acrescenta: "Faltou-me quem me dissesse então, como em 1929 Roquette Pinto aos arianistas do Congresso Brasileiro de Eugenia, que não eram simplesmente mulatos ou cafusos os indivíduos que eu julgava representarem o Brasil, mas cafusos e mulatos doentes."

A doença, porque diminúi a inteligência, porque reduz a capacidade de esfôrço, porque empobrece e consequentemente dificulta o cultivo intelectual, aprofunda' cada vez mais as separações sociais. Prevení-la e cŏmbatê-la, restabelecendo-se a saude de dois terços da nossa população, constituem providências essenciais a serem tomadas com urgência, para o pleno florescimento da democracia no Brasil.

Na dificil e demorada solução dêsse problema também se inclúi a questão alimentar. Perdoai-me, a êsse respeito, algumas minudências de caráter especializado, sem as quais flicariamos a argumentar no vácuo. Pode-se considerar, para média individual, em cada família brasileira, o valor de 3.000 calorias como mínimo indispensável da ração energetica. Pois bem: mesmo na Capital de São Paulo, se há familias operárias em que a média, em 1935, ultrapassava êsse mínimo, não eram poucas, pois representavam $37 \%$ dos casos investigados, as em que a despesa individual se colocava abaixo de 2.600 calorias. Note-se que estamos falando do operariado desta Capital, da Manchester brasileira. Em lugares economicamente menos favorecidos - como o 
Recife, - a média apurada, verdadeiramente incrivel, foi de 1.646 calorias, isto é, cêrca de metade da ração mínima de energia. Se descessemos a outros pormenores - à ração proteínica, à de minerais, ou à de vitaminas - maior seria o nosso espanto. A propósito destas últimas, das famigeradas vitaminas, cantadas em prosa e verso, dir-se-á que, apesar de tudo, são escassas entre nós as avitaminoses, com? a xeroftalmia, o beriberi, o escorbuto e o raquitismo. Sim, é bem provável. Mas, com impedir as avitaminoses francas, não se exgotam as funções das vitaminas, pois que a sua carência mitigada e crônica, como sucede em relação à nossa gente, se traduz por deficiências físicas e psíquicas que, embora menos dramaticas, roubam ao Pais uma alta parcela de vitalidade e de energia construtiva.

\section{Desce a Genética à arena política}

Em referência à suposta superioridade genética das famílias abastadas, Henry Wallace, o famoso ex-vice-presidente dos Estados Unidos, tendo dedicado alguns anos ao estudo da Genética, e outros tantos ao dos problemas sociais, adverte: "A hereditariedade é um fato, e não podemos escapar aos seus ef eitos. Mas eu creio que todo geneticista digno dêsse nome concordará em que o meio também é um fato, e que não podemos verdadeiramente avaliar o lugar da hereditariedade, antes de fornecermos um ambiente favorável para que os cromosomas e os "gens" efetuem o seu trabalho."

Reunio-se em Edinburgo, em agosto de 1939, ou seja nas vésperas da deflagração do último conflito mundial, um congresso científico ao qual compareceram os mais reputados geneticistas da atualidade. Ao encerrarem as suas sessões, em que altos problemas biológicos foram examinados, julgaram os congressistas que a sua tarefa ficaria incompleta se êles permanecessem na torre de marfim da ciência pura, e se, como fazem, infelizmente, não poucos intelectuais, se es- 
quivassem de descer ao nivel do cidadão comum, para discutir os vitais problemas da política. No importante manifesto que então lançaram ao mundo, êsses cientistas de tão larga compreensão de suas funções na vida social, aceitando embora a premissa básica da existência de diferenças hereditárias entre os seres humanos, declaram que o verdadeiro aperfeiçoamento da humanidade depende de mais profundas mudanças nas condições sociais e nas atitudes dos homens, e que não pode haver fundamento válido para esti-marmos e compararmos o valor intrinseco dos diferentes individuos, sem condições ecônomicas e sociais que proporcionem aproximadamente iguais oportunidades a todos os membros da coletividade, em vez de os estratificarem desde o nascimento em classes com privilégios desiguais. Nos termos ainda do mesmo documento, a melhora biológica $\mathrm{e}$ psíquica dos elementos da comunidade, jamais será alcançada se a produção não se organizar principalmente para beneficiar o consumidor e o trabalhador; se as condições do trabalho não se adaptarem às necessidades dos pais, e se a organização das habitações, das cidades e dos meios de comunicação não fôr reformada no sentido do benefício das gerações infantis.

No mundo científico, tais ideias não pretendem mais à originalidade, pois eram já correntes antes mesmo de 1939, e se repito aqui as palavras mais ou menos textuais do famoso manifesto, é tão só para prestigiar os seus conceitos com a autoridade mundial dos respectivos signatários.

Eu mesmo, meses antes daquela reunião, escrevia que o problema urgente do Brasil não é o da raça e sim o da higiene e da educação. Não podemos dizer mal do nosso plasma germinativo antes de lhe havermos facultado os elementos essenciais ao seu pleno florescimento fenotípico. Temos que dar a cada indivíduo, na cidade ou na roça, o confôrto e a saude indispensáveis às manifestações da vida civilizada. Melhorar a habitação de cada familia, combatendo, pelo tratamento causal, o fenômeno urbano dos mocambos, das favelas e dos cortiços, o fenômeno rural dos ranchos sem prote- 
ção, sem luz, sem água e sem limpeza. Curar a população; resguardá-la contra os assaltos da malária e do amarelão, da tuberculose e da lepra, da sífilis e do alcoolismo. Promover condições que the permitam alimentar-se satisfatòriamente, recebendo cada dia, não só a dose necessária de calorias para o trabalho, mas ainda as proteinas, os minerais e as vitaminas que estimulam o organismo em tôdas as atividades funcionais e que despertam no homem o gôsto pela vida e pelo trabalho criador. E a todos facultar os benefícios da educação, levando o ensino, sob as suas múltiplas feições, às crianças, aos moços e mesmo aos adultos de quaisquer pontos do território nacional.

\section{O círculo vicioso da autocracia}

Por nos terem faltado, até êste momento, em proporções adequadas, êsses dois sustentáculos da democracia - a saude e a educação - nossa gente, ao que se murmura com o intuíto de "justificar" e de "continuar", se encontra agora imatura para as funções políticas que lhe cabem no regime democrático.

E por que motivo, meus senhores, por que motivo tem escasseado ao brasileiro aqueles dois benefícios? A resposta (a não ser que pertençamos a uma espécie particular, sub-humana) só pode ser uma. E' porque não se chegou a praticar ainda, entre nós, na devida plenitude, o regíme democrático. Visto que o povo não votava, ou quando votava não o fazia livremente, havia desinterêsse da parte dos eleitos (ou dos que se auto-elegiam) em resolver os problemas do povo. Falava-se muito, isso sim; discursava-se nas manifestações "espontâneas" e nos estádios de futebol. Mas pouco se fazia. De sorte que ficavamos, e ainda continuamos neste círculo vicioso: o povo, porque é incapaz, não pode viver em democracia; mas, enquanto não vier a viver em democracia, continuará sendo incapaz. 


\section{$-143-$ \\ 0 terceiro pilar}

Falta ainda, entretanto, um pilar, o terceiro, sem o qual as instituições democráticas não se conservarão em equilíbrio. Já foi dito que das três graças da democracia de 1789, - a liberdade, a igualdade e a fraternidade, - a liberdade é a primeira. Passando das graças, que estão dentro da democracia, para os pilares, que formam a sua base, também reclamo a presença da liberdade. "The last, but not the least." O homem de hoje que a menospreze, ou não é psicológicamente sadio, ou foi privado dos benefícios da educação. A ausência consentida do último pilar significa a ausência prévia de pelo menos mais um dos outros dois.

A liberdade é o oxigênio da vida democrática. Se há (o que me parece fantasia) nações democráticas que consigam viver sem liberdade, trata-se, por certo, de alguma exótica produção da fauna política, decorrente do fenômeno biológico das mutações. Será uma democracia anaeróbia, em cuja atmosfera qualquer de nós se sentiria asfixiado.

Discute-se sôbre se o amor à liberdade constitúi, ou năo, parte integrante da natureza humana. A meu ver, êsse sentimento está implícito no ámago da mais rudimentar das. sociedades, tanto quanto no embrião das aves se contêm as asas em estado potencial. Que o embrião não aborte, que a sociedade amadureça, e as asas oportunamente se abrirão, no movimento espontâneo e natural do vôo.

$O$ fato é que todos aqueles regimes que detestamos, detestam por sua vez a liberdade. Hitler declarou, um dia: “A Providência ordenou que eu seja o maior liberador da humanidade. Estou libertando os homens da ambição da liberdade..."

Só a liberdade é fecunda, pois os sistemas anti- liberais estancam a produção específicamente humana. O que êles edificam - quando edificam - pertence apenas às manifestações sociais vegetativas, às expressões mecânicas da atividade, e não à vida cívica e moral. "Os períodos de liberdade suprimida ou oprimida (como declarou Benedetto 
CROCE) contribuem para a produtividade geral da história, sómente na medida em que a supressão ou a opressão não é absoluta e completa." Na produção científica, por exemplo, - eterno motivo da gabolice da Alemanha - o nazismo, mesmo depois de recrutar, à fôrça, elementos estrangeiros, perdeu o grande e decisivo pário da bomba atômica: venceram as nações amantes da liberdade. Da criação literária, já se ocupou AlFiERI, no século XVIII, acentuando que a literatura que viceja em tôrno dos tiranos, tem sido sempre uma arte de medíocres.

A tirania, enfim, porque tolhe a liberdade, é em si mesma estéril e esterilizante.

\section{A árvore das liberdades}

Mas de que liberdades se trata, quando se fala no florescimento das democracias?

A preocupação dominante entre os escritores do passado, era a liberdade de palavra. Sem dúvida que a palavra, como as trombetas de Israel, é fôrça irresistível, e, a rigor, na liberdade que se lhe dê estão de certo modo contidas tôdas as demais. Convirá, entretanto, que sejamos analiticos, e que principiemos pela base. "O míto grego (faz notar Whitehead) foi claro. O revoltado Prometeu tentou conquistar, não a liberdade de imprensa, mas o'fogo, que cozinha e aquece."

A liberdade de dispôr de si, é, entre tôdas, a primordial, e, para conseguí-la a investigação científica tem sido o mais prestimoso auxiliar da humanidade. Roberto Millikan, estudando recentemente as extraordinárias perspectivas que a ciência está abrindo, no sentido da liberdade humana, comenta: "Nos Estados Unidos, empregavam-se em 1929 cêrca de 13,5 cavalos-hora por dia, per capita, - o equivalente a 100 escravos humanos para cada um de nós; na Inglaterra a média era de 6,7; na Alemanha, de 6,0; na França, de 4,5; no Japão, de 1,8; na Rússia, de 0,9; na China, de 0,5. Ai está (diz o reputado cientísta) aí está porque não mais conduzimos os 
nossos navios por meio de escravos amarrados aos remos, como faziam os Gregos e os Romanos. Ai está porque não mais escravisamos populações inteiras, como faziam os $\mathrm{Fa}$ raós. Ai está porque frequentam as escolas secundárias dos Estados Unidos, hoje, dez vezes mais rapazes e moças, do que em 1890 - mais de cinco milhões hoje, meio milhão na quela época. Ai está porque temos presentemente um dia obreiro de oito horas, em lugar de um dia de dez, de doze e de catorze horas, como naquele tempo."

Essa progressiva libertação física, que entre nós está apenas começando, há de acompanhar-se da ruptura, igualmente progressiva, dos grilhões econômicos que ainda encadeiam a maioria da nossa população. Mais uma vez irá a política bater às portas da ciência. "Ao passo que a velha ordem (diz um economista americano) se baseava na competição, a nova ordem da ciência torna possivel, pela primeira vez, um esfôrço cooperador de criação, no qual todos ganham e ninguem perde." "Já a ciência (continua êle) fez maravilhas para elevar o padrão de vida e de conhecimentos; mas as fôrças naturais ocultas são tão grandes, que podemos nos considerar apenas no início das nossas realizações." O operário médio, nos Estados Unidos, pode hoje comprar sete vezes mais coisas, com o seu salário, do que podia fazê-lo em 1840, e tem mais do que o dôbro das suas possibilidades de 1910 .

Esses e outros "records" de libertação física e de aumento na capacidade econômica popular, são a resposta objetiva aos que julgam impossível melhorar condignamente o padrão geral de vida, sob o regime da liberdade democrática.

\section{Liberdade de cultura e liberdade política}

Pari-passu, havemos de nos empenhar na conquista da liberdade de cultura. Está implícita nesse propósito a efetivação da conhecida fórmula - "igual oportunidade para todos." Efetivação real e concreta. Téóricamente, damos 
a todos os moços que atingem a idade de dezoito anos a mais completa igualmente de direitos. Podem competir entre si no concurso à lotação das escolas superiores; podem tomar parte na disputa aos cargos eletivos; podem candidatar-se livremente aos postos de govêrno ou aos embates gerais na luta pela subsistência. Mas não vemos, ou fingimos que não vemos a profunda desigualdade que prevaleceu nos seus longos dezoito anos anteriores, em que, pelo simples acaso. do nascimento, uns tiveram tôdas as facilidades para a garantia e o incremento da saude e da cultura, ao passo que outros não tiveram nenhuma. Enquanto não enfrentarmos corajosamente êsse problema, afim de atenuarmos os males que da sua existência decorrem, não teremos fornecido à democracia o material humano que ela está a exigir.

Inclua-se igualmente nos pressupostos democráticos o respeito à espontaneidade do espírito juvenil, à liberdade do seu pensamento. Impor à juventude escolar, como ainda fazemos entre nós, o estudo de velharias, inúteis quer do ponto de vista pragmático, quer como cultura, é uma violência inominavel, e só alcança esterilizar o espírito criador das novas gerações. Será processo eficaz para a fabricação de inimigos do. progresso e de louvaminheiros da tirania, mas não para a formação de homens livres, capazes de iniciativa e de crítica. Educação ditatorial, ciência ditatorial, literatura ditatorial, patriotismo ditatorial, são coisas igualmente falsas e nefastas.

No ápice, afinal, veremos amadurar a liberdade política, o fruto mais característico dessa árvore de liberdades que a democracia tem o dever de cultivar. Por mim, subscrevo sem reservas a opinião de Lincol.s : um govêrno livre é melhor do. que um bom govêrno.

Nas nações ditatoriais, a liberdade política se torna, como se sabe, inteiramente inútil, visto que, inspirado por sua congênita sabedoria, o ditador é infalivel. Nem crítica, nem votos contra... Daí a censura. Daí o "partido único", em que todos opinam com a mais rigorosa unanimidade, $\mathrm{e}$ em que ninguem precisa pensar, pois a palavra de ordem, definitiva e irrecorrivel, vem de cima, cruzando no ar com 
a palavra de apláuso, cálida e pegajosa, que da bôca dos bajuladores sobe a acariciar a vaidade do supremo chefe.

Quando muito, em matéria de divergência de opinião e isso a título de derradeira homenagem ao cadáver da democracia - aceitam-se dois partidos: um no poder, outro na cadeia...

\section{Desloquêmo-nos para a esquerda}

Liberdade democrática não significa, está claro (e creio que nunca significou), liberdade absoluta. E' pressuposto inelutável da vida em comum saber conservar o justo equilíbrio entre o indíviduo e a sociedade, entre o direito e o dever, entre a liberdade e a responsabilidade. Sob todos os aspectos (inclusive sob o aspecto econômico), os extremos do individualismo, assim como os desvarios da socialização, revelam-se igualmente prejudiciais ao progresso, à cultura e ao bem estar dos homens.

Temos vivido até hoje, no Brasil, sobretudo em referência à distribuição do confôrto, excessivamente acomodados do lado direito. Agora, pelas mudanças radicais nas condições da vida e da opinião pública, mudanças essas aceleradas em virtude dos violentos abalos da guerra, precisamos nos deslocar, e vamos certamente nos deslocar para a esquerda. Isto, porém, assim o espero, sem abolição de nenhuma das nossas liberdades fundamentais. Nem a física, nem a econômica, nem a do pensamento, nem a política. Devemos conservar tôdas elas, ainda que com as restrições reclamadas pelas circunstâncias e aceitas pelo consenso geral.

Sem a abolição de nenhuma liberdade, disse eu. Peço perdão: retifiquemos, ou, melhor, esclareçamos. Há uma liberdade contra a qual nos devemos insurgir por tôdas as formas ao nosso alcance. Refiro-me à liberdade de destruir a democracia, à liberdade de matar a liberdade. Pode suceder que surjam por aí, a pleitear o retrocesso (como agora mesmo está sucedendo), cidadãos que nasceram sem espinha, ou que sofrem da incurável nostalgia do ergástulo. A êsses, seguindo o velho conselho de Rousseau, obriguêmo- 
los a serem livres, ainda que pela fôrça. Quanto aos que porventura reaparecerem na praça pública, envergando ou não camisas coloridas, e candidatando-se ao lugar mais ou menos vago de "chefe nacional", creio que não pode haver tergiversações. Praticado o competente exame de sanidade mental, seu destino se decidirá, conforme o resultado: manicômio ou penitenciária.

\section{Conclusão}

Meus senhores! Já vos devo ter fatigado com o meu rançoso didatismo. Vamos concluir. Antes de fazê-lo, porém, quero evocar com William Phelps e convosco, uma das cenas mais impressionantes dos "Miseráveis", de VrTor Hugo. Certa noite, no Clube, um fanático de Napoleão I, Marius, proferia longo discurso laudatório:

"- Sêde justos, meus amigos (dizia êle). Ser o império de semelhante imperador, que magnífico destino para um povo, quando êsse povo é a França e quando alia o seu gênio ao gênio de tal homem! Aparecer e reinar; marchar e triunfar; ter cada Capital por entreposto; tomar os seus granadeiros e fazê-los reis; decretar a queda de dinastias, transfigurar a Europa... Fazer do império francês o sucessor do império romano; conduzir o Grande Exército; mandar às legiões que voem sôbre a superfície da Terra, como uma montanha manda as suas águias para todos os lados... Vencer, governar, fulminar; ser na Europa uma espécie de povo redoirado pela glória; fazer ecoar na história uma clarinada de Titães; conquistar o mundo duplamente, pela conquista e pelo resplendor ... Isso é sublime, e que coisa, meus senhores, que coisa existe que possa ser maior?"

"- Ser livre," respondeu Camberre.

Digamos, para terminar, sem a ênfase romântica de Vitor Hugo, mas com igual convicção: esforcem-se os moços que vivem esta fase decisiva da evolução da humanidade, no sentido de preservar e de aumentar as conquistas da civilisação, procurando fazer do Brasil uma nação sadia, culta e de homens livres. O que equivale a dizer: uma nação definitivamente integrada na democracia. 